\title{
Nurses' Knowledge and Practice about Infection Control In Outpatient Clinics of Governmental Hospitals at Al-Mukalla City - Yemen
}

\author{
Haddad, S.A. El-Hebshi ${ }^{1}$, Hoda D Fahmy ${ }^{2}$, Soad A Sharkawy ${ }^{3}$ \& Abdullah Alhanshi ${ }^{4}$. \\ 1. Assistant lecturer Community Health Nursing, Faculty of Nursing, Hadhramout University- Yemen. \\ 2. Professor of Community Health Nursing, Faculty of Nursing, Assiut university-Egypt. \\ 3. Assist Prof Community Health Nursing, Faculty of Nursing, Assiut University, Egypt. \\ 4. Associate Prof Community Health Nursing, Faculty of Nursing, Hadhramout University, Yemen.
}

\begin{abstract}
Background: The role of the nurse is very important in breaking the chain of infection, and they can do this by applying proper infection control practices. The study aimed to assess the knowledge and practice of outpatients Nurses about infection control. Subjects \&Methods: Descriptive research design was carried out in this study at Ibn seena hospital, Almukalla and University Hospitals for Maternity and childhood that located in Almukalla city. The total number was 50 nurses selected as a convenient sample. Two tools were used in data collection The First tool is the structured questionnaire it content Participants' knowledge related to nosocomial infection the Second tool was the observation checklists to assess the nurses practice. Results: revealed that $80 \%$ of the studied sample has not attended seminars or conferences about infection control and 54\% of them was given vaccine for hepatitis, and $90 \%$ had poor knowledge and practice. There was no statistically significant difference between knowledge and practice Conclusion: It is concluded that the studied nurses had poor knowledge and practice. Also, there is positive correlation between knowledge and practice about infection control. Recommendation: Should be apply in services programs about infection control to all nurses in outpatient's clinics, also establish national guidelines for infection control practice in outpatient clinics.
\end{abstract}

\section{Keyword: Infection Control, Knowledge, Practice, Nurses, Outpatients Clinics.}

\section{Introduction}

Hospital acquired infections (HAIs) are significant problems throughout the world and are increasing in developing countries. WHO's report revealed that health-care settings with limited resources reported Health Care Associated Infections rates higher than in developed countries. Hospital acquired infections can be caused by bacteria, viruses, fungi or parasites. This organism may already be present in the patient's body or may come from the environment, contaminated hospital equipments, Healthcare workers or other patients (Fijan \& Turk, 2012)

NIs have significant consequences on patients, their families, and the community as a whole. The most common consequences of NIs are increased morbidity, mortality, and length of hospitalization [4, 8]. Such consequences contribute substantially to raise both the direct and indirect cost of the health care services, which result in additional costs to treat infected cases. Hence, such issue wastes the available resources which are not already enough, especially in developing countries (Iliyasu et al., 2016)

Universal precautions and infection control are designed to reduce the risk of transmission microorganisms from both recognized and unrecognized sources of infections. These precautions promote hand washing and use of gloves, masks, eye protection, and gowns when appropriate for patient contact (Allegranz et al., 2010)
About $4.9 \%$ of health care workers are exposed to needle stick per year and it is calculated that 24,000 and 8600 Egyptian health care team are infected yearly with hepatitis $C$ virus and/or hepatitis $B$ virus, respectively). Because health team workers are more susceptible for blood borne pathogens so, it is important to prevent them from infection (Rosenthal et al., 2012). The rate of (HAIs) In Yemen is up to almost $60 \%$, according to some studies, $80 \%$ of infected people are dying because of such infection (MOHP 2014)

Prevention and control of infections are important concerns for all types of health care agencies. Several studies have demonstrated that there are cost savings to health care facilities that practice good infection control. Acute care hospitals have organized infection control programs. The infection control practitioner is usually a nurse with advanced training in infection control practice and methods for tracking the source and spread of infection. Each department in the hospital must have written policies and manual procedures for the control of infection, usually updated annually (Van der Berg \& Daniels 2013)

The infection control nurse has multi-faceted duties. She is involved in planning, monitoring, evaluating, updating, and educating the staff infection control measures, risk of infection and major infectious diseases in the work. She sets general infection 
control policy, provides input into specific infection control issues and preventing outbreaks of infection in healthcare settings and the community (Mohamed, 2013)

\section{Significance of the study}

- In Hadhramout Almukalla city, the infectious diseases at governmental hospitals become increasingly high during 2012, including respiratory diseases 33840 cases, as well as both hepatitis B\&C 176 cases and diarrhea 28271cases (Ministry of health and population- Yemen 2014)

- As a result for the events and war in Yemen, the number of patients entering to outpatient's hospital has increasing rapidly causing the probability of occurrence of infections in the hospitals.

\section{Aim of the study}

The study aimed to

- Assess the knowledge of nurses about infection control

- Assess the practice of nurses about infection control.

Research questions

- Do nurses have good knowledge about infection control?

- Do nurses have good performance about infection control?

- Is there a relation between nurse's knowledge and practice?

\section{Subjects \& Methods \\ Study Design}

Descriptive research design was used in this study.

\section{Setting \& Sample}

The study was carried out for nurses in outpatient clinics at Hadhramout Governmental Hospitals as Ibn seena, Almukalla and University Hospitals for Maternity' childbirth \& childhood that are located in Almukalla city-Yemen. The study was conducted for 50 nurses are who working in these hospitals as a convenient sample.

\section{Tools for Data collection}

Three tools were used in this study:

Tool I: Part I: The structured questionnaire which was developed by the researcher after reviewing the relevant literature to collect information from the nurses including personal characteristic: as name, age, sex, residence, qualifications and years of experience.

Part II: Nurses' knowledge related to nosocomial infection as definition causes, chain of infection, measures which will used to control nosocomial infection among patients in the outpatient clinics and any previous infection control courses. It contains 60 items about infection control, vaccination, sterilization \&most common diseases that affect nurses in outpatients and general precautions that prevent the spread of infection.

\section{Scoring system}

The knowledge questionnaire contains 2 types of questions; the first type was statements to which respondents answer with either true or false, the second type was open ended questions where the respondents freely reply to the questions. The model answers where extracted from all answers after summarizing them. The scoring system was developed. For each item two grades were awarded for the complete correct answer and one grade for none complete and zero for an incorrect answer. The total knowledge score was determined by (Kotb, 2004 \& Alhanshi, 2010) who estimate the answer by taking points as the following:

$\begin{array}{ll}\text { - Poor } & <50 \% \\ \text { - Fair } & 50 \%-<70 \% \\ \text { - Good } & 70 \% \text { and more }\end{array}$

Tool: II Observation checklists were used by the researchers to collect data related to nurse's practices as regard the application of infection control measures, it includes universal precautions as hand washing, wearing and removing sterile gloves, wearing mask and applying gown. The Observation checklists include done, not done and.

A scoring system of practice was one grade for done practice and zero for not done.

- Unsatisfactory $<80 \%$

- Satisfactory $\quad 80 \%+$

Pilot study

A pilot study was carried out for $10 \%$ of nurses who were included in the sample to test the clarity of the questionnaire and the responses of nurses and to estimate the length of time which is required to complete the questionnaire.

Validity of the study

The tools were reviewed to ascertain their validity by five experts in medical and nursing sciences, who reviewed the instrument for their clarity, relevance, comprehensives, understanding and applicability.

\section{Reliability}

Reliability of tool I \& tool II was assessed using alpha - cron-bach test the internal consistency r1 $=0.842 \&$ r2 0.7889 .

Field work

Under agreement letters from faculty of nursing to the hospitals the researcher started to collect data from $15^{\text {th }}$ of April, to $25^{\text {th }}$ July 2015 . The researcher met the nurses in the health education room at each hospital in the morning shift .Then he explained the aim of the study to the nurses and after that he read the questionnaire carefully and distributed it to the nurses to fill it. The researcher was available in the class to answer any question and for further 
explanation. The length of the time needed to fill the sheet was ranging from 15-20 minute. After that, the nurses' performance was assessed and observed by the researcher at outpatients' clinics in 2 days/ week every 3-5 nurses were assessed/ day.

\section{Ethical consideration}

The purpose of this study was explained for nurses of the studied sample. Nurses have ethical rights to participate or refuse participation in the study; oral consent was taken from all nurses who participated in the study to ensure active participation and cooperation during implementing of the program and informed that the information obtained will be confidential and used only for the purpose of the study.

Statistical Analysis

The obtained data were reviewed, prepared for computer entry, coded, analyzed and tabulated. Descriptive statistics (frequencies, percentage, mean and standard deviation) were done using computer program SPSS version 20, Excel 2010. Chi square test were used to compare different variables and pear correlation coefficient. It was considered significant when P-values were less than 0.05.

\section{Results}

Table (1): Distribution of the studied nurses according to their socio-demographic characteristic 2016 (n=50)

\begin{tabular}{|c|c|c|}
\hline Socio-demographic characteristic & No. & $\%$ \\
\hline \multicolumn{3}{|l|}{ Age } \\
\hline$<30$ years & 26 & 52.0 \\
\hline 30 years and more & 24 & 48.0 \\
\hline Range & \multicolumn{2}{|c|}{$20-38$} \\
\hline Mean+SD & \multicolumn{2}{|c|}{$28.7+4.4 .8$} \\
\hline \multicolumn{3}{|l|}{ Sex } \\
\hline Male & 27 & 54.0 \\
\hline Female & 23 & 46.0 \\
\hline \multicolumn{3}{|l|}{ Qualification } \\
\hline Bachelor of Nursing & 12 & 24.0 \\
\hline Technical Nursing & 35 & 70.0 \\
\hline Technical Assistant Nursing & 3 & 6.0 \\
\hline \multicolumn{3}{|l|}{ Years of experience } \\
\hline$<5$ & 33 & 66.0 \\
\hline$>5$ & 17 & 34.0 \\
\hline Range & \multicolumn{2}{|c|}{$1-10$} \\
\hline Mean+SD & \multicolumn{2}{|c|}{$4.64+3.45$} \\
\hline \multicolumn{3}{|l|}{ Attend seminars or conferences about infection control } \\
\hline Yes & 10 & 20.0 \\
\hline No & 40 & 80.0 \\
\hline Number of seminars $\quad n=10$ & & \\
\hline One seminars & 7 & 70.0 \\
\hline Two seminars & 3 & 30.0 \\
\hline \multicolumn{3}{|l|}{$\begin{array}{l}\text { Vaccine given for the nurse against virus hepatitis or any } \\
\text { infectious disease }\end{array}$} \\
\hline Yes & 27 & 54.0 \\
\hline No & 23 & 46.0 \\
\hline Number of dose were given & & \\
\hline Single dose & 13 & 48.1 \\
\hline Two & 9 & 33.3 \\
\hline Three & 5 & 18.5 \\
\hline \multicolumn{3}{|l|}{ Organization that provided the vaccine $(n=27)$} \\
\hline Hospital & 14 & 51.9 \\
\hline Health office & 13 & 48.1 \\
\hline
\end{tabular}


Table (2): The studied nurses' knowledge about outpatients infection control $(n=50)$.

\begin{tabular}{|c|c|c|}
\hline Items & No. & $\%$ \\
\hline \multicolumn{3}{|l|}{ The meaning of infection } \\
\hline Complete correct answer & 4 & 8.0 \\
\hline Incomplete correct answer & 28 & 56.0 \\
\hline Incorrect answer & 18 & 36.0 \\
\hline \multicolumn{3}{|l|}{ Define acquired infections } \\
\hline Complete correct answer & 1 & 2.0 \\
\hline Incomplete correct answer & 37 & 74.0 \\
\hline Incorrect answer & 12 & 24.0 \\
\hline \multicolumn{3}{|l|}{ Types of infection } \\
\hline Self infection & 3 & 6.0 \\
\hline Acquired infection & 7 & 14.0 \\
\hline All the above & 32 & 64.0 \\
\hline Don't know & 8 & 16.0 \\
\hline \multicolumn{3}{|l|}{ Mode of infection transmission \# } \\
\hline Air & 35 & 70.0 \\
\hline Mouth & 34 & 68.0 \\
\hline Infected person & 16 & 32.0 \\
\hline Body orifices and wounds & 11 & 22.0 \\
\hline \multicolumn{3}{|l|}{ The meaning of Infection Control } \\
\hline Incorrect & 14 & 28.0 \\
\hline Incomplete correct & 36 & 72.0 \\
\hline Complete correct & 0 & 0.0 \\
\hline \multicolumn{3}{|l|}{ The main objective of infection control } \\
\hline Limitation of infectious microbes at one place & 9 & 18.0 \\
\hline Preventing the spread of infectious microbes & 25 & 50.0 \\
\hline Prevent the reproduction of infectious microbes & 1 & 2.0 \\
\hline Control the impact of infectious microbes & 13 & 26.0 \\
\hline Don't know & 2 & 4.0 \\
\hline
\end{tabular}

\# More than one answer

Table (3): The studied nurses' knowledge about infection control $(n=50)$.

\begin{tabular}{|c|c|c|}
\hline Items & No. & $\%$ \\
\hline \multicolumn{3}{|l|}{ Meaning of nosocomial infections } \\
\hline Complete correct & 3 & 6.0 \\
\hline Incomplete correct & 37 & 74.0 \\
\hline Incorrect & 10 & 20.0 \\
\hline \multicolumn{3}{|l|}{ Factors that affect the occurrence of nosocomial infections \# } \\
\hline Period of patients residence in hospital & 35 & 70.0 \\
\hline Continuous uses of antibiotics & 24 & 48.0 \\
\hline Bad uses of urinal catheters & 17 & 34.0 \\
\hline Not to pay attention to hygiene for hospital and workers & 1 & 2.0 \\
\hline \multicolumn{3}{|l|}{ Sources of nosocomial infection \# } \\
\hline External( environment surrounding the pt) & 22 & 44.0 \\
\hline Internal (from pt body secretion) & 27 & 54.0 \\
\hline Hospitals & 7 & 14.0 \\
\hline Unsterilized materials & 0 & 0.0 \\
\hline \multicolumn{3}{|l|}{ Types of protective precautions \# } \\
\hline Wearing gloves & 34 & 68.0 \\
\hline Hand washing & 32 & 64.0 \\
\hline Wearing mask & 22 & 44.0 \\
\hline Wearing gown & 9 & 18.0 \\
\hline
\end{tabular}

\# More than one answer 
Table (4): The studied nurses' knowledge about hand washing and wearing gloves Yemen 2016 ( $n=50$ ).

\begin{tabular}{|c|c|c|}
\hline Items & No. & $\%$ \\
\hline \multicolumn{3}{|l|}{ Purpose of Hands washing \# } \\
\hline Remove dust and germs from hands & 36 & 72.0 \\
\hline Limiting the spread of infection in hospitals & 9 & 18.0 \\
\hline Reduce microbes on the hands to a minimum level & 5 & 10.0 \\
\hline \multicolumn{3}{|l|}{ Hand washing routine \# } \\
\hline Between care the patient to another & 43 & 86.0 \\
\hline Before and after taking the samples & 35 & 70.0 \\
\hline When hands contamination with blood and body fluids & 34 & 68.0 \\
\hline Before starting work & 10 & 20.0 \\
\hline Before wearing gloves & 44 & 88.0 \\
\hline After removing gloves & 50 & 100.0 \\
\hline Before and after any procedure & 42 & 84.0 \\
\hline \multicolumn{3}{|l|}{ The materials used when washing hands } \\
\hline Correct & 45 & 90.0 \\
\hline Incorrect & 5 & 10.0 \\
\hline \multicolumn{3}{|l|}{ Time takes to wash hands $(20-30$ second $)$} \\
\hline Correct & 17 & 34.0 \\
\hline Incorrect & 33 & 66.0 \\
\hline \multicolumn{3}{|l|}{ Routine of using gloves \# } \\
\hline When handling material contaminated with blood & 28 & 56.0 \\
\hline When hand was contaminated & 17 & 34.0 \\
\hline When caring patient( dressing, injection) & 16 & 32.0 \\
\hline
\end{tabular}

\# More than one answer

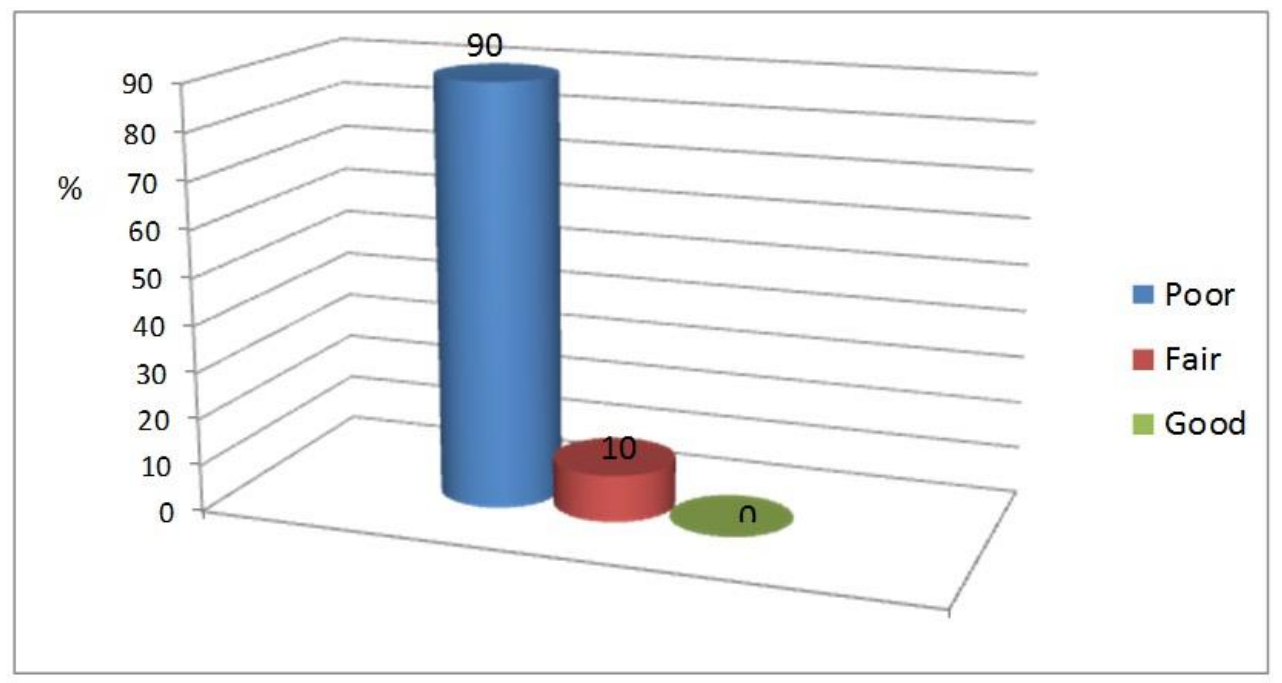

Fig (1) Total score of knowledge about infection control among study Participants Yemen 2016 (n=50) 


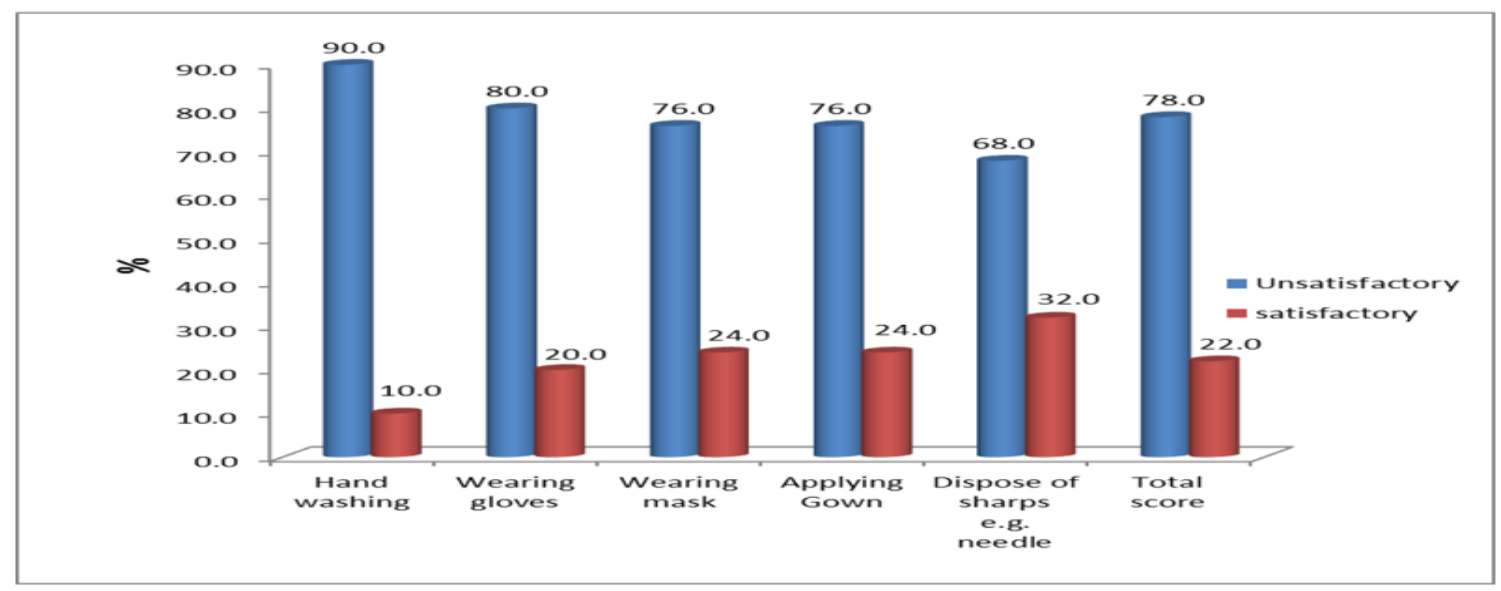

Fig (2): Total score of practice about infection control among studied nurses at Yemen 2016(n=50)

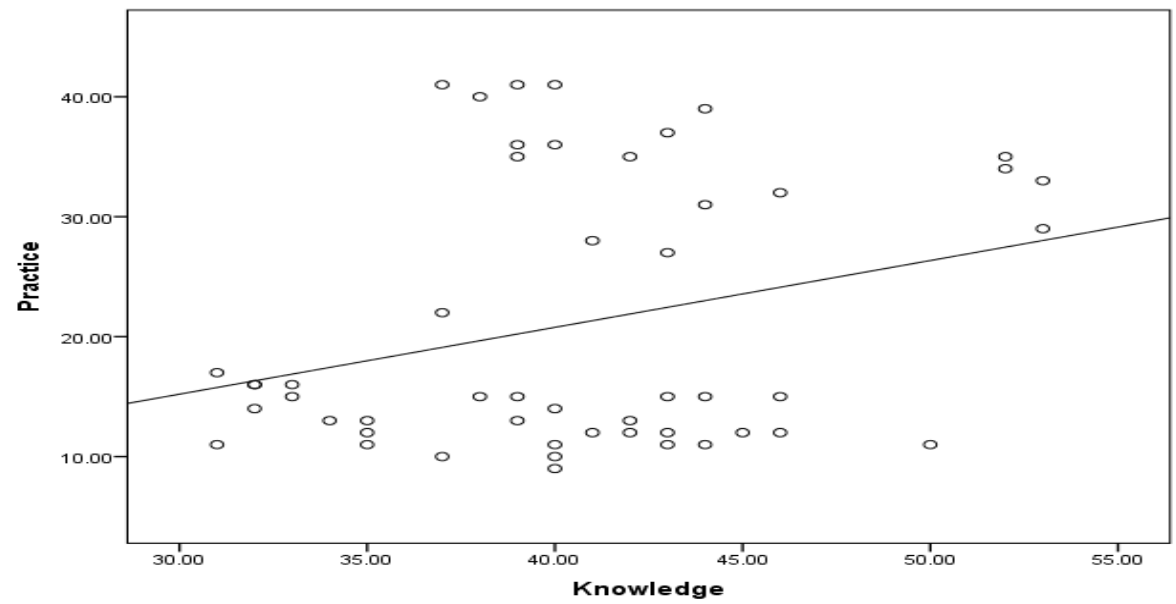

Fig (3): Pearson correlation coefficient between knowledge and practice about IC among studied nurses at Yemen 2016

Table (1): Showed the socio-demographic characteristics of the studied nurses. It was noticed that $52 \%$ of the studied nurses were in the age group $<30$ years. As well as $0 \leqslant \%$ of them were Male. In addition, it was clear that $(70 \%)$ of the studied nurses were technical nursing and $66 \%$ of them had more than 5 years of experience. One fifth (20\%) of them attended seminars or conferences about infection control

Table (2) Showed the nurses' knowledge about infection control. It was revealed that only $8 \%$ of the studied nurses knew the complete correct meaning / definition of infection. In addition, 64\% of them know all types of infection. Regarding the mode of infection transmission, it was noticed that air and mouth are the most common mode of infection transmission $(70 \%, 68 \%)$ respectively. Regarding the main objective of infection control, half $(50 \%)$ of the studied nurses said that preventing the spread of infectious microbes
Table (3): Displayed the nurses' knowledge about nosocomial infection it was found that about three quarters $(74 \%)$ of the studied nurses had incomplete meaning of nosocomial infection. In addition, $70 \%$ of them knew that the period of the patient's residence in a hospital is the main factor that affects the occurrence of nosocomial infections. Regarding the main source of nosocomial infection, more than half (54\%) of studied nurses said that it is internal from patient secretion. Regarding the type of protective precautions $68 \%, 64 \%$ and $44 \%$ said wearing gloves, washing hand and wearing mask respectively.

Regarding the knowledge of the studied nurses about hand washing and wearing gloves in table (4) it was observed that $72 \%$ of the studied nurses knew remove dust and germs from hands was considered from the purpose of hand washing, and all the studied nurses $(100 \%)$ mentioned that after removing gloves as routines of hand washing, In addition to the materials that were used through hand washing this table 
revealed that $90 \%$, had the correct answer. Also regarding the time taken to wash hands, it was clear that $34 \%$ had the correct answer.

Fig (1): Showed the total score of knowledge about infection control. It was observed that the vast majority $(90 \%)$ of the study sample hadn't the score of knowledge about infection control

Fig (2): Observed studied nurses according to their score of practice about infection control. It was found that the majority has unsatisfied practice in applying all type of universal precaution.

Fig (3): Pearson correlation coefficient between knowledge and practice about infection control among studied nurses. This figures illustrate that the positive correlation between knowledge and practice among studied nurses about infection control $(\mathbf{r}=\mathbf{0 . 2 8 5})$. It was revealed that there was a statistical significant correlation between knowledge and practice $(\mathbf{P}=\mathbf{0 . 0 4 5})$

\section{Discussion}

Hospital acquired infections (HAIs) are significant problems throughout the world and are increasing in developing countries. WHO's report revealed that health-care settings with limited resources reported to have Health Care Associated Infections rates higher than those in developed countries (Fijan \& Turk, 2012)

The finding of present study revealed that more than half of studied nurses in age are less than thirty years. According to years of experience, it was found that about two thirds of nurses had an experience less than 5 years, this result agrees with (Iliyasu et al., 2016) study in Nigeria who reported that more than half of nurses' in age are less than twenty- five years. Related to years of experience they disagree with the current study because they found that about one third of nurses had less than five years of experience.

In relation to sex and the educational level of the studied nurses, more than half of them were male, while more than two thirds had technical nursing institution education, because in some culture's people refuse that the girl enter the nursing profession which is difficult for the girl to work during the night shifts, these findings agree with (Alrubaiee et al., 2017 \& Shehata, 2011) study in Yemen and Minia who reported that, most of nurses included in the study were male with diploma of nursing education, and less than half of nurses included in the study were females.

Regarding to nurse's knowledge about infection control, the current study revealed that more than half of them had incomplete knowledge about the accurate meaning of infection, and less than two third of them knew the different types of infection. Less than three quarter of them knew the mode of infection transmission and half of them knew the main objective of infection control, this study agrees with (Elkaradawy 2012) who reported that, more than two thirds of nurses don't know the main sources of infection, and mode of transmission.

Regarding the nurse's knowledge related to nosocomial infection, the current study showed that about three quarters of them had incomplete knowledge about meaning of nosocomial infection, while more than half of studied nurses stated internal infection (from patient secretion) as source of infection, This result agrees with (El sayd et al., 2014) who noted that nurses' knowledge were higher among younger and newly graduated nurses.

The current study findings also show that less than three quarters of the studied sample knows the Purpose of hand washing, while the majority know the routine of hand washing, also the majority of nurses know the materials used during hand washing. These findings are in disagreement with (Ahmed, 2016) and who conducted their studies at Assiut-Egypt about the assessment of health team knowledge and practices about infection control in maternal child health Centers, and reported that most health teams generally had poor knowledge about hand washing.

Regarding the total score of knowledge among the studied sample included in the current study, majority of the studied nurses had poor score of knowledge about infection control, another study agreed with

(El sayd et al 2014 \& Ahmed, 2016) study in Egypt who reported that the majority of the participants had low to moderate knowledge about the total score of infection control.

Regarding the total score of practice about infection control among studied nurses in the present study. The findings report that the studied nurses have unsatisfied practice in all types of universal precautions. The present study are agree with (Alrubaiee et al., 2017) study in Yemen who observed that fair practice regarding infection control measures and disagrees with (Mohammed 2011) who revealed that good practice score levels were obtained by the studied nurses.

The current study revealed that there was not any a statistically significant difference in relation between the total score of knowledge among the studied nurses and the total score of practice $(\mathrm{P}=0.12)$, Also a study was conducted by (Mohammed, 2011) who reported that there is no statistically significant relationship between nurse's knowledge and practice which is in agreement with the present study.

The present study showed that there was a positive correlation between knowledge and practice $(\mathrm{r}=0.285) \quad(\mathrm{P}=0.045)$, Another study disagrees with 
the present study was conducted by and (Hess, et al., 2013) who reported that there is no significant correlation scores of knowledge and practice.

\section{Conclusion}

Based on the result of the current study, the studied nurses had poor knowledge and practice. Also there is no significant relation between knowledge and their practice, and positive correlation between knowledge and their practice about infection control.

\section{Recommendation}

The study recommended that:

Provide inservices programs about infection control to all nurses in outpatient's clinics, also to establish national guidelines for infection control Knowledge and practice in outpatient setting.

\section{References}

1. Ahmed S., (2016): Assessment of Knowledge and practice of health team toward infection control in blood banks at Assiut city, theses for partial fulfillment of the requirements for master degree in community health nursing, Faculty of nursing, Assiut University.

2. Alhanshi A., (2010): Developing and evaluating an education program about AIDS for Hadhramout University student in Yemen. Doctorate thesis in Nursing. Faculty of Nursing. Assiut University.

3. Allegranz, B., Sax, H., Bengaly, L., Richet, H., Minta, D., Chraiti, M., Sokona, F., GayetAgeron, A., Bonnabry, P., \& Pitte, D., (2010): Successful Implementation of the World Health Organization Hand Hygiene Improvement Strategy in a Referral Hospital in Mali, Africa. Infection Control and Hospital Epidemiology; 31(2) pp. 133-141

4. El Sayed M., Anwar M., \& Ahmed M., (2014): Infection control awareness among healthcare providers in family health settings in Shebin Elkom district, Menoufia Governorate, Egypt, Menoufia. Med journal Volume: 27(4) Pages: 840-840.

5. Elkaradawy S., Healy G., \& Abdel Wahab M., (2012): Effect of an infection control educational programme on anesthetists' attitude and anesthetics field bacterial contamination, Egyptian Journal of anesthesia 359-363.

6. Fijan S., Turk S., (2012): Hospital textiles, are they a possible vehicle for health care-associated infections? International journal of environmental research and public Health; 14: 3330-3343.

7. Gamil Alrubaiee, Anisah Baharom, Hayati Kader Shashair, Shafee Mohd Daud \& Huda Omer Basaleem (2017): Knowledge and practice of nurse regarding nosocomial infection control measures in private hospitals in Sanaa city Yemen, Safety in Health, Research Article.

8. Hasan K., (2010): Study of knowledge, attitude and practices of nursing students regarding pulmonary tuberculosis as a basic to develop, implement and evaluate an educational program for them in Assiut city. Faculty of nursing Assiut University.

9. Hess A., Shardell M., Johnson J ., Thom K., Roghmann M., Netzer G., Amr S., Morgan D., Harris A., (2013): A randomized controlled trial of enhanced cleaning to reduce contamination of healthcare worker gowns and gloves with multidrug-resistant bacteria.Infection Control and Hospital Epidemiology; 34: 487-493.

10. Iliyasu G., Dayyab F., Habib Z., Tiamiyu A., Abubakar S., Mijinyawa M., (2016): Knowledge and practices of infection control among healthcare workers in a tertiary referral center in North-Western Nigeria. Ann Afr Med.; 15(1):34.

11. Khalifa K., (2011): Assessment of nurse's performance regarding reducing or prevention of nosocomial infection for patients with cancer suggested nursing protocol, submitted to partial fulfillment for the requirements of the master degree in medical surgical nursing, faculty of Nursing, Assiut University

12. Kotb S., (2004): Evaluation of an educational program among the workers working in cement factory in Assiut city for prevention of occupational hazards. Doctorate thesis in Nursing. Faculty of nursing

13. Mohamed H., (2013): :Health Personal Behavior in Implementing Universal Precaution for HIV/aids Disease Prevention in Meatega Hospital Tripoli, Science Journal of Medicine and Clinical Trials volum2012, 9pages.

14. Mohammed S., (2011): Assessment of nurse's knowledge and performance regarding infection control during milk formula preparation and its effect on neonates at EL-Minia University hospital, faculty of Nursing Assiut University.

15. MOHP Ministry of health and population Republic of Yemen (2014).

16. Rosenthal, V., Maki, D., Mehta \& Apisarnthanara Y., (2012): International Nosocomial Infection Control Consortium (INICC) report, data summary of 36 countries, American Journal of Infection Control. 40: 396407.

17. Shehata H., (2011): Assessment of nurses Practice related to infection control during vaccination in children at EL-Minia, faculty of Nursing Assiut University. Thesis submitted in 
partial fulfillment of the requirement for master degree in pediatric nursing.

18. Van der Berg L., \& Daniels F., (2013): do nursing students know and practice the Universal Precautions to prevent transmission of infectious agents Curationis 36(1), p 7. In university of the Western Cape, South Africa. From: http://dx.doi.org/ 10.4102/curationis.v36i1.99. 